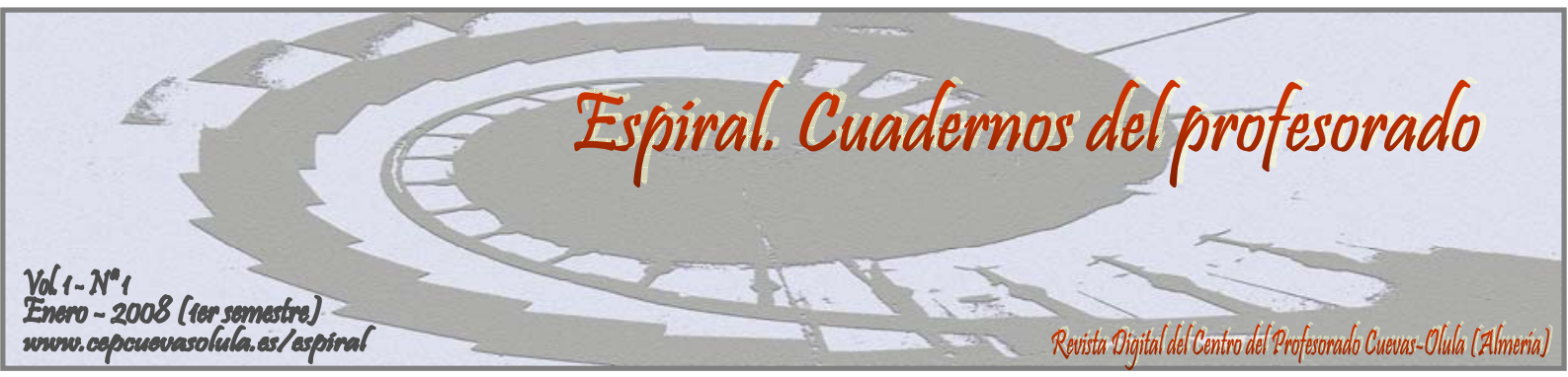

\title{
LA VIDA ECONÓMICA Y SOCIAL DURANTE LA POSGUERRA EN OLULA DEL RÍO (1939-1949).
}

\section{Ramón Jesús Lorente Castillo}

\author{
I.E.S. El Palmeral, Vera (Almería)
}

Enviar correspondencia a: rjlorente@gmail.com

RESUMEN: En este artículo se intenta dar una visión de la situación económica, demográfica y social del pueblo de Olula del Río durante la terrible década de los años cuarenta del siglo XX. Partiendo de una visión general, particularmente de la política autárquica emprendida por el régimen de Franco tras la Guerra Civil, y a través del análisis de diversos documentos custodiados por el Archivo Municipal de la localidad y de testimonios orales, se intenta mostrar como era la vida en Olula del Río en la mencionada década: los años del hambre.

Palabras clave: Autarquía, I.N.I., Falange.

\begin{abstract}
This article attempts to give an overview of the economic, demographic and social life of people of Olula del Río during the terrible decade of the forties in the twentieth century. Based on an overview, particularly of autarkic policies undertaken by the Franco regime after the Civil War, and through the analysis of various documents held by the Municipal Archives in the locality and oral testimony is an attempt to show how life was in Olula del Río in this decade: the years of famine.
\end{abstract}

Key words: Autarky, I.N.I., Falange.

\section{CONSIDERACIONES PREVIAS.}

En primer lugar, hemos de decir que para la realización de este trabajo, hemos contado con la amable colaboración de Diego, empleado del Ayuntamiento y con Anselmo Requena, gran conocedor de la historia del pueblo y de los archivos municipales de Olula del Río.

En segundo lugar, queremos excusarnos de antemano pues este trabajo puede adolecer de una falta de rigor en la investigación, ya que hay grandes lagunas en lo que a documentos se refiere, a pesar del esfuerzo llevado a cabo por Antonio Casquet, encargado de la Biblioteca municipal que se encargó de ordenar el archivo, pero no hay que olvidar que el material que se encuentra en el mencionado municipio ha sufrido dos traslados en los últimos veinte años, traslados realizados sin miramiento alguno hacia los fondos de los archivos. En un principio, quisimos estudiar los libros de actas, pero éstos no han aparecido. Por lo tanto, este trabajo ha sido realizado basándonos en los escasos documentos encontrados y unos pocos testimonios orales de personas que vivieron en esta década, aunque a este autor le hubiese gustado contar con más tiempo para haber podido hablar con más testigos directos de la vida del pueblo en los años escogidos para el artículo. (Quizás más adelante, yo mismo o algún otro investigador, tenga ese preciado tiempo para dejar constancia directa de una parte de la historia del pueblo que se conserva en las vivencias personales y que si no se remedia se perderá con nuestros mayores). 
Por último, quisiera dedicar el presente artículo a aquellas personas que tuvieron que soportar unas condiciones de vida deplorables durante más de diez años, después de la Guerra Civil Española y que gracias a las penalidades que ellas soportaron $\mathrm{y}$ al duro esfuerzo que realizaron, nosotros podemos tener hoy en día una calidad de vida mejor. Sirva también para recordar a los que se fueron ya para que nadie olvide unos años que fueron duros para todos y todas y que ojala que no se tengan que repetir. También sirva este trabajo para que los jóvenes aprecien lo que hoy tenemos y para que nuestras conciencias se abran y podamos ayudar a aquellos que actualmente sufren las mismas condiciones de vida que nuestros mayores tuvieron que soportar no hace mucho tiempo.

\section{1.- INTRODUCCIÓN.}

La sensación que tenemos cuando revisamos los documentos de los primeros años cuarenta del siglo XX en Olula del Río es la de un intento absoluto de control por parte de las nuevas autoridades y el patente esfuerzo por reorganizar la vida municipal de acuerdo con los nuevos esquemas de los vencedores. Así, obedeciendo a la órdenes provenientes de distintos órganos de control, el Ayuntamiento procede a elaborar distintos censos con el objeto de determinar el número de vecinos que hay en el pueblo, el número de cabezas de ganado, el número de viviendas y su estado, el número de molinos, de industrias, de quintales métricos de trigo, avena, cebada, etc., producidos y así un largo etcétera.

Tras finalizar la Guerra Civil, el nuevo Estado franquista, de carácter totalitario, puso en marcha un nuevo tipo de política económica que perduró hasta los primeros años de la década de los cincuenta: la autarquía. Ésta consistía en lograr el autoabastecimiento en todos los niveles de la vida económica y era dirigida y controlada por la administración estatal.

Hay autores que afirman que dicha opción en la política económica se debió a las necesidades impuestas por la Guerra Civil: "Esta política estuvo determinada por los desastres económicos de la guerra. En tal caso se trataría de una solución de emergencia obligada por los acontecimientos $y$, por tanto, de naturaleza coyuntural "1.

\footnotetext{
${ }^{1}$ Bahamonde Magro, Á. (1993). La sociedad española de los años 40. Cuadernos del mundo actual. Historia 16. Madrid. 1993. p. 12.
}

Dicha política se continuó aplicando tras finalizar nuestra última contienda civil debido al estallido de la Segunda Guerra Mundial y a las circunstancias políticas del momento, al vincularse España emocional, política y económicamente al Eje.

Sin embargo, finalizada la contienda mundial, no hubo ningún cambio en el discurso económico del régimen franquista, sino que se utilizó el bloqueo político que los aliados decretan contra el régimen de Franco como excusa para continuar con la politica autárquica. Al bloqueo político se sumaría, por tanto, el bloqueo económico por parte de los "enemigos de la patria". "A partir de 1945 se añadieron nuevos elementos al discurso autárquico. Ahora se alude al boicot internacional de los aliados contra el régimen de Franco. La negativa del mercado mundial a comerciar con España obligó a una nueva prórroga de la autarquía económica. Hubo que esperar hasta principios de los años cincuenta para que se produjera la apertura del capitalismo español." ${ }^{2}$.

Esta situación económica estaba en consonancia con "el ideal de economía cuartelaria" que tanto gustaba a Franco, pues a las condiciones internas y externas hay que añadir que los regímenes políticos totalitarios defienden el nacionalismo económico. No en vano Mussolini afirmaba que "la autoderminación de los pueblos no se comprende si no está respaldada por la independencia de su economía respecto del mercado exterior"3.

El ideal autárquico pretendía lograr la autosuficiencia económica, es decir, no depender de las de importaciones, o al menos, limitarlas al máximo, no dudando en sustituir los productos extranjeros por los nacionales, aún cuando fuesen estos últimos de peor calidad. Por lo tanto este intervencionismo estatal iba mucho más lejos de la imposición de barreras aduaneras y pretendía controlar totalmente el comercio exterior.

Este tipo de política económica que convertía en arbitrarias las concesiones de divisas y las licencias de importación posibilitaba la generalización de la corrupción, que en el plano social encontraba su traducción en las prácticas

\footnotetext{
2 Ibid., p. 12.

3 Avilés Fernández, M., Madrazo Madrazo, S., Mitre Fernández, E., Palacios Martín, B. \& Redondo Castro, I., (1985). El Siglo XX. De la Segunda República a nuestros días, Nueva Historia de España (p. 281). Madrid. EDAF.
} 
estraperlistas del mercado negro. Este comercio ilegal, es decir, al margen de los canales "oficiales" permitió tanto el nacimiento de grandes fortunas, como un pequeño desahogo a las economías menos favorecidas.

El dirigismo estatal acabó por desembocar en una economía altamente burocratizada. Sus dos piezas básicas eran el Servicio Nacional del Trigo y la Comisaría de Abastecimientos y Transportes. Cada nueva institución creada tenía su contrapartida en un paralelo aumento de la corrupción y del estraperlo. La creación en septiembre de 1940 de la Fiscalía de Tasas, a pesar de que configuró una abundante legislación para reprimir el mercado negro, fracasó en su intento. En 1943, según datos oficiales, un $30 \%$ de la cosecha era desviado hacia el mercado negro como símbolo de todo el conjunto, las cartillas de racionamiento, instauradas en la primavera de 1939, perduraron hasta 1951, ejemplificando el fracaso de uno de los lemas más repetidos por la propaganda: Que en ningún hogar falten la lumbre y el pan ${ }^{4}$.

La extensión del mercado negro afectaba a las economías familiares, pero también a las pequeñas y medianas empresas que no estuvieran bien relacionadas con determinados centros de poder. Los estrangulamientos en el suministro de materias primas y energía estaban a la orden del día. La imposibilidad de obtener licencias de importación obligaba al contrabando para obtener los recursos necesarios. Sólo una buena cobertura política aseguraba un buen funcionamiento empresarial $^{5}$.

El Instituto Nacional de Industria (I.N.I.) se creó por la ley de 25 de septiembre de 1941 y tenía como objetivo "propulsar y financiar en servicio de la nación la creación y resurgimiento de nuestras industrias, en especial de las que se propongan como fin principal la resolución de los problemas impuestos por las exigencias de la defensa del país o que se dirijan al desarrollo de nuestra autarquía económica, ofreciendo al ahorro español una inversión segura $y$ atractiva(...) para respaldar nuestros valores nacionales y realizar los programas de nuestro destino histórico”. En realidad, su actividad en un primer momento se centró llevar a su máximo exponente la política de sustitución de importaciones, sin valorar sus elevados costes, sobre todo en el sector vinculado a la defensa

\footnotetext{
${ }^{4}$ Bahamonde Magro, op. Cit., p. 14.

${ }^{5}$ Ibid., p. 14-15.
}

nacional. Contó con el lastre secular de la ausencia de una tecnología nacional.

Una de las constantes de la época es la persistencia de un déficit público. La insuficiencia de los ingresos ordinarios del Estado contrastaba con el incremento de los gastos ordinarios y extraordinarios. La solución se encontró en un incremento de la circulación fiduciaria, a través del siguiente circuito: emisión de deuda pública - suscripción de la misma por la banca privada - pignorización en el Banco de España -emisión de nuevos billetes. Es a partir de 1947 cuando asistimos a un cierto ordenamiento monetario con la elevación del tipo de interés y un mayor control en la concesión de créditos bancarios $^{6}$.

Los años cuarenta están, pues, marcados por un complejo haz de dificultades $y$ estrangulamientos que limitaron el crecimiento económico.

Así, la reconstrucción posbélica, se retrasó considerablemente. Hasta 1952, la renta per cápita en pesetas constantes de 1935 no alcanzará los valores de éste último año ${ }^{7}$.

Esta medición esconde una realidad social de carácter dual. Fueron los grupos sociales más desfavorecidos quienes soportaron el deterioro de la evolución económica. Un marco dual en el que las figuras de los nuevos ricos, bien situados políticamente, contrasta con situaciones de extrema pobreza. En 1947 la subsistencia básica diaria de una familia trabajadora con dos hijos se elevaba a 12'5 pesetas aproximadamente, mientras que en 1951 su coste se había incrementado en un $100 \%$. Sin embargo, los salarios no habían seguido el mismo ritmo ${ }^{8}$.

Como resultado de todo ello, fueron los asalariados los que se encontraron con un panorama económico desastroso y que la contracción del consumo se hacía especialmente sensible en productos como el trigo, las patatas, el azúcar y la carne, que se redujeron aproximadamente el $50 \%$ del periodo $1931-35^{9}$. En el marco de las relaciones laborales, éstas se caracterizan por el incumplimiento, por parte de los empresarios de las normas dictadas por las autoridades.

\footnotetext{
${ }^{6}$ Ibid., p. 18

${ }^{7}$ Ibid., p. 18.

${ }^{8}$ Ibid., p. 19.

${ }^{9}$ Ibid., p. 19.
} 
Otro dato a destacar es la carencia en la nutrición de los habitantes de las medianas y grandes ciudades. Esta carencia se veía agravada por que muchos pobres vendían el pan, y sobre todo, el aceite y azúcar para comprar luego otros alimentos de menos valor. En Olula del Río, como en otras zonas rurales, existía una práctica extendida que consistía en engordar cerdos que eran sacrificados y las familias menos pudientes vendían los jamones para comprar tocino.

\section{2.- SITUACIÓN DEMOGRÁFICA.}

ECONÓMICA

Olula del Río no escapa a la realidad nacional que acabamos de ver. Hemos encontrado algunos documentos que son significativos y que nos muestran, desde el punto de vista oficial, la situación económica del pueblo en esta década. Tenemos una petición del Centro de Reclutamiento, Movilización y Reserva de Almería, fechada el 4 de mayo de 1940 que refleja el siguiente estado de cosas.

El pueblo de Olula del Río producía oficialmente en 1940, 24 quintales métricos de patatas, 4.099 de aceite, 22 de garbanzos, 11 de judías, 300 de tocino, 600 de trigo, 182'5 de leche, 60 de cebada, 300 de maíz, 20 de alfalfa y otros forrajes, 20 de harina de trigo, 20 de harina de maíz, 200 de paja, 8.100 de esparto y 109 huevos. Poseía 80 cabezas de ganado lanar, 90 de caprino y 200 de porcino. Existían 5 hornos de cocer pan que podían producir, mediante su sistema antiguo, 5.000 kilos de pan en 24 horas. También había 18 industrias dedicadas en su mayor parte al trabajo del mármol, aunque también destaca una fábrica de chocolate y 4 talleres para la reparación de automóviles, que en total daban trabajo a 121 obreros. En esta época no había ningún surtidor de gasolina y los combustibles utilizados en el ámbito doméstico era básicamente la leña de pino del que se obtenían anualmente unas 340.000 ramas.

Sin embargo, no vamos a creer que tenía una economía próspera y mucho menos autosuficiente. Pues en el mismo documento encontramos las necesidades estimadas para el consumo anual, que son las siguientes: 82.125 quintales métricos de patatas, 24.000 de aceite, 2.025 de garbanzos, 515 de judías, 2.400 de arroz (del que no existía producción en el término municipal), 265 de sal (de la que tampoco había producción), 1.272 de tocino, 840 de vino (que tampoco se producía en el pueblo), 127 de azúcar, 2.563'75 de trigo, 795 de leche, 400 de cebada, 9.640 de maíz, 80 de alfalfa y otros forrajes, 80 de harina de trigo, 80 de harina de maíz, 800 de paja y 20 de esparto.

Si comparamos las cifras de producción y consumos vemos que hay una diferencia abismal entre ellas, por lo que Olula se muestra deficitaria en todo, menos en la producción de esparto.

Bien, estas son las cifras declaradas oficialmente y que nos pueden dar una idea de la capacidad económica del pueblo. Pero podemos hacernos la pregunta de si realmente se corresponde con la realidad, ya que quien pide el informe es el Ejército con la intención de conocer la riqueza del pueblo y es natural que se intentase por parte del Ayuntamiento, o al menos, de los habitantes del pueblo, de ocultar la verdadera realidad económica y presentar un panorama desolador en lo que concierne a las necesidades alimenticias. Cabe destacar al respecto que el único producto que aparece claramente con superávit es el esparto y sabemos que éste era una fuente de ingresos importante para la economía agraria e interesaba que se vendiese, que se exportase.

Estas sospechas que acabo de formular se ven confirmadas con otros informes encontrados en los archivos.

En una estadística del ganado existente en el término municipal hecha por la Junta Local de Fomento Pecuario del 5 de mayo de 1941, encontramos que hay 305 ovejas, 320 cabras, 275 cerdos, 1.630 aves y 1.430 conejos. Y en otra del 5 de junio de 1942 tenemos 1 caballo, 3 yeguas, 20 mulos, 20 muías, 15 burros, 105 burras, 139 ovejas, 425 cabras, 269 cerdos y 1.780 aves de corral.

Vemos que en el informe de 1941 no aparecen caballos, mulos, burros, aves de corral ni conejos, por lo que sólo podemos comparar las cabezas de ganado porcino, ovino y caprino. Destaca la diferencia entre el número de cabezas que es más reducido en el informe del año 1941, el que se dirigía al ejército. Las otras dos estadísticas las consideramos más fiables pues se realizaron para las juntas locales y en principio no había ningún interés por ocultar las cabezas que se poseían.

Además, por si nos queda alguna duda sobre la pregunta que nos hacíamos más arriba, hemos encontrado un oficio de la Jefatura Provincial del Servicio de Carnes, Cueros y Derivados del 3 de 
mayo de 1949 en el que se hacen constar literalmente los defectos siguientes:

"1 ${ }^{\circ}$ Una considerable ocultación, no es posible que 104 ovejas tan solamente tengan 3 crías de 1 a 2 años y ninguna de menos del año...

$2^{\circ} \quad$ No me remite debidamente cumplimentada la carpeta que debía venir acompañando al censo. (...) Por todo ello devuelvo a Ud. todo ello para que en el plazo de 5 días sea remitido nuevamente a esta Jefatura una vez rectificado en todos los sentidos los defectos de que el referido censo adolece".

Si en 1949 existía la práctica de ocultar datos a la administración central, o por lo menos provincial, ¿por qué no debió ocurrir lo mismo antes, en 1940 ?

Por otra parte, hemos contado con testimonios orales de gentes que vivieron aquellos años y que nos dicen que era costumbre tener animales de corral en casa y que se ocultaban a las autoridades por miedo a que fueran requisados, ya que de una manera directa o indirecta, dichos animales suponían una fuente de ingresos para las maltrechas economías familiares.

Por otro lado, también tenemos tres informes, dos emitidos por la Junta Municipal de Falange en 1944 y otro por la Alcaldía en 1948 en los que podemos encontrar más pruebas de la penosa situación económica del pueblo.

El primero de dichos informes es interesante por cuanto nos revela el sistema de financiación que existía para las corporaciones locales. Así en septiembre de 1944, la Junta Municipal de F.E.T. y de las J.O.N.S. se financiaba con los ingresos del repartimiento general de utilidades de las subastas, de los aprovechamientos del esparto y de pastos, así como de las participaciones de tributos del Estado, ascendiendo los ingresos y gastos a 53.490,37 pesetas para ese año.

En este informe encontramos también una respuesta negativa a la pregunta de si es posible la implantación de nuevos tributos. Además es interesante por cuanto que en él se mencionan la necesidad de construir un grupo escolar ("es muy necesario y de suma urgencia en esta localidad la construcción de un Grupo Escolar, ya que se carece en la misma de locales para las Escuelas y de viviendas para los Señores Maestros"'); de una casa cuartel de la Guardia Civil ("También es muy precisa la construcción de un edificio destinado a este fin, ya que el existente en la actualidad es de un señor particular y no reúne las condiciones adecuadas tanto de emplazamiento como de las más elementales necesidades"); de realizar la captación y conducción de aguas potables ("Se precisaría realizar trabajos de alumbramiento de aguas "en el Monte Público denominado "Pinatar de Sierra Maimón" con el fin de destinarlas al abastecimiento del vecindario y los sobrantes se destinarían al riego de los pagos de Huytar Mayor y Menor, hoy de secano por falta de agua "); la realización de obras de riego ("Estas se podrían construir viniendo personal técnico $e$ indicarán el lugar para realizar los trabajos y con estos aumentar el caudal de agua hoy existente en el Monte Público, precisando para ello forzosamente por su gran coste la ayuda económica del Estado") y por último se reclaman obras de alcantarillado ("Al realizar las obras para la traída de agua potable destinada al abastecimiento del vecindario se precisaría igualmente la construcción del alcantarillado").

Todo ello nos revela una importante carencia de infraestructuras higiénico-sanitarias, de educación e incluso de protección, al no contar los guardias civiles del pueblo con un cuartel "propio". Esta carencia de infraestructuras se hará crónica, pues el demandado grupo escolar no será realidad hasta 1963, año en el que se inauguraron las primeras fases del actual Colegio Público "Antonio Relaño" y los guardias civiles tuvieron que continuar "viviendo del alquiler" hasta el año 1975 en el que se trasladaron al actual cuartel sito en la Calle Madrid.

Es evidente la carencia total de una mínima infraestructura de servicios municipales, que hoy en día vemos como normales en un país desarrollado, como el alcantarillado, la existencia de agua corriente, un colegio, un cuartel de la Guardia Civil, agua para riego, e incluso, y no lo menciona el informe, el tener unas calles asfaltadas, o al menos, para la época empedradas o adoquinadas. Parece que estamos hablando de otros lugares más propios del Tercer Mundo que de nuestro país, pero no debemos olvidar que no hace mucho tiempo, por ejemplo, un servidor que no tiene tantos años, recuerda el jugar en la calle sin asfaltar, el día en el que se hicieron las zanjas para instalar la red de alcantarillado, el día en el que se inauguró el actual alumbrado eléctrico de las calles, etc. por no seguir mencionando servicios y dependencias sociales que se han construido y cuya ejecución se ha llevado a cabo en los últimos veinte años. 
Otro documento interesante es una circular interna del Frente de Juventudes fechada en 5 de noviembre de 1944 en la que se menciona la existencia de tres escuelas masculinas con un total de 96 alumnos, otras tantas femeninas con un total de 121 alumnas y una escuela mixta a la que asiste un número aproximado de 25 alumnos. El pueblo también contaba con 20 centros de trabajo del Frente de Juventudes a los que acudían 32 obreros menores de 21 años. En la misma circular se reconoce que el número de afiliados al Frente de Juventudes es de 39 y que el ambiente con respecto a esta organización es regular, argumentando a modo de excusa que existía "gran retraso en la organización que hoy ya está reorganizándose con toda rapidez". El número de habitantes que se reconoce para el pueblo os de 2.182 y la situación económica del mismo se califica como muy buena, aunque no pueden decir lo mismo de la situación de las cuentas del Frente de Juventudes que están a cero, aunque eso sí, les deben 1.200 pesetas de atrasos por parte del Ayuntamiento. El nivel cultural del pueblo se afirma que es regular y a ello se intenta poner remedio solicitando la colaboración de los maestros nacionales para la Formación de equipos deportivos y cuadros artísticos "que estimularán el desarrollo de nuestra formación"...

Como vemos, en materia cultural sólo se intenta formar equipos deportivos y cuadros artísticos que no son ni más ni menos que la creación de un equipo de fútbol y un grupo de bailes regionales. Parece que para algunas autoridades municipales no existen otros medios para elevar el nivel cultural de los pueblos.

En cuanto a calificar la situación económica del pueblo como muy buena, nos parece una exageración, teniendo en cuenta las carencias en infraestructuras de las que adolecía el pueblo y que veíamos en el anterior documento y que el salario para un aprendiz era de unas cuatro pesetas diarias y para un obrero especializado de once pesetas cuando un pan costaba veintidós pesetas.

Por último vamos a estudiar una petición que realiza el Ayuntamiento el 15 de mayo de 1948, dirigida al Ministerio de Trabajo en la que se solicita la creación de una Farmacia en esta localidad y para apoyar dicha solicitud, los ediles municipales argumentan que "el pueblo consta de 2.040 habitantes, que su principal fuente de riqueza es de carácter industrial, derivada de las 18 fábricas de aserrar mármol, de cuatro talleres mecánicos y de los medios de tracción mecánica $y$ de sangre que dan trabajo a más de 300 obreros fijos, que se encuentran en su totalidad al cubierto de todos los seguros sociales..." En este documento se culpa a los poderes públicos anteriores de no haber creado la solicitada farmacia, ni tan siquiera un botiquín de urgencia. Vemos también como se alteran los datos reales para intentar que las peticiones sean más sólidas, pues en el informe se dice que Macael, lugar donde estaba la farmacia que correspondía al municipio de Olula del Río, distaba de éste unos seis kilómetros, cuando en el peor de los casos, la distancia entre ambos pueblos es de cuatro kilómetros.

Por todo ello se dice de manera velada que la atención sanitaria en el pueblo era deficiente ("Así las cosas tanto los obreros como los demás vecinos de esta localidad no pueden atender con la debida puntualidad y asiduidad los casos de accidentes, enfermedades y demás que se vienen presentando..."). Además, en este informe se nos revela otro dato que deja evidente la carencia de infraestructuras propias de la época, pues se afirma que "hay que tener en cuenta que entre el pueblo de Macael y éste pasa el Río Almanzora y al no existir puente de ninguna clase, se da el caso de quedar incomunicados varios días, como está ocurriendo en la actualidad por las abundantes lluvias de esta zona que, aún continúan y ello hace que sea completamente imposible poder atravesar dicho río".

En relación con esta petición cabe añadir que en materia de administración sanitaria, Olula del Río no tenía plena autonomía ya que, como hemos visto, no se disponía de farmacia en el pueblo y se dependía de la de Macael; en lo que atañe a los servicios médicos, se compartía galeno con Urrácal, al igual que el practicante desde 1910. A este respecto hay que decir que el médico durante esta década fue el Dr. Arturo Herrero Sánchez, y tal como señala un informe de Antonio Ortega Martínez, Jefe Local de la Falange en 1944, el citado doctor "no actuó en la política activa no antes, ni durante el periodo rojo, siempre fue de derechas y persona de orden, siendo perseguido por los marxistas muy duramente en su persona, sus familiares y en sus intereses...". Hablaremos más adelante de él al tratar las personas que ocupaban cargos importantes en la vida pública del pueblo en esta década. También se compartían con el citado pueblo vecino, tal y como hemos dicho antes más arriba, los servicios del practicante y ello dio pie 
a una petición oficial por parte del alcalde de Olula del Río en 1942 para que se nombrase un practicante para el pueblo. Su petición es desestimada, ya que éste ya estaba nombrado y era el de Urrácal, pero se aconseja al alcalde desde el Colegio Oficial de Practicantes de Almería la manera de resolver el problema asistencial. "De una manera particular, sí podría resolverse, pues yo podría mandar a ese pueblo un practicante joven, apto e inteligente, siempre que el Sr. Alcalde (...) me garantizara abonarle al mismo las consignaciones de las dos plazas auxiliares, ya que para resolver legalmente lo relativo a estos pagos (...) aquí en Mancomunidad puedo darle la seguridad de que harían por no enterarse". Podemos ver que también se llegaba a acuerdos no muy ortodoxos y rayando la legalidad en esta época y como no, en materia burocrática se hacía "la vista gorda" cuando interesaba.

Con esta cuestión y aunque quizás no tenga nada que ver, desde la época de la Reconquista, Olula y Urrácal estuvieron unidas desde el punto de vista administrativo, pues el 1 de octubre de 1492, los Reyes Católicos, otorgaron los lugares de Olula del Río y Urrácal a Don Luis de la Cerda, duque de Medinaceli.

Para terminar de analizar la situación económico-productiva de Olula del Río vamos a estudiar la evolución de la población desde 1940 a 1948, basándonos en tres documentos. El primero de ellos data de diciembre de 1940 y fue realizado por una Junta Municipal del Censo de Población cuya composición también nos revela quienes constituían las fuerzas vivas del pueblo. Volviendo al censo, encontramos que Olula del Río tenía censados en 1940 a 2.152 habitantes. 1.036 varones y 1.116 hembras. Desgraciadamente, no hemos hallado documento alguno que nos indique la edad de estas personas por lo que nos ha sido imposible hacer pirámide de población alguna. Bien, siguiendo con nuestros documentos, el segundo de ellos ya lo conocemos, es la circular del Frente de Juventudes con fecha del 5 de noviembre de 1944. Casi cuatro años después en la que se afirma que Olula cuenta con 2.040 habitantes. Y por último, el tercer documento es el informe que eleva el Sr. Alcalde en 1948 al Ministerio de Trabajo pidiendo la concesión una farmacia en el que se hace constar la cifra de 2.040 habitantes, por lo que deducimos que el número de éstos no ha cambiado en cuatro años. Aunque desconocemos si hubo algún cambio en la estructura de la población.

En términos más que generales podemos decir que Olula del Río experimentó un descenso en su número de habitantes. Vuelvo a repetir que desconocemos la causa de este descenso, pudo ser provocado por un aumento de la mortalidad, por un poco probable descenso de la natalidad o por la existencia de una corriente migratoria. Podemos intuir que este descenso pueda deberse a que hubiese habitantes del municipio que estuviesen detenidos o en campos de trabajo; pero para ello tuvo que darse el caso de que fueran censados erróneamente en $1940 \mathrm{y}$ posteriormente, al comprobarse su ausencia, se les dio de baja. Pero dado el celo con el que los componentes de la Junta del Censo Municipal realizaron su trabajo, es posible que este descenso sea debido a otras causas. En cuanto a la natalidad y la mortalidad, hemos encontrado una relación con el número de nacimientos y defunciones, así como el número de matrimonios correspondiente a la década que nos ocupa.

\section{3.- MUNDO LABORAL Y EMPRESAS.}

Con el final de la Guerra Civil, los sindicatos son abolidos en toda España y los trabajadores quedaban encuadrados obligatoriamente en los sindicatos verticales dirigidos por miembros de Falange.

La experiencia del reformismo social desde principios de siglo y el discurso nacionalsindicalista del falangismo confluyeron en la creación de la primera estructura de la Seguridad Social, en 1943, por el ministro de trabajo.

En los años cuarenta se dio una situación de sobreexplotación de la clase trabajadora por parte de los empresarios, identificados plenamente con los vencedores de la contienda civil. Se producían situaciones muy arbitrarias como el poder ser despedido por falta de respeto al superior, indisciplina, desobediencia, fraude, deslealtad, negligencia, etc.

Desde 1945 resultaba evidente que el ideal autárquico estaba agotado. Los asalariados habían visto un descenso de su poder adquisitivo, ya de por sí especialmente bajo, conforme la política dirigista quedaba distorsionada por el avance del mercado negro.

En el municipio de Olula del Río existieron durante la década de los años cuarenta unas dieciocho fábricas de aserrar el mármol que 
dieron empleo a unos trescientos obreros, sin embargo, esto no quiere decir que la explotación del mármol fuese una actividad industrial lucrativa, pues las empresas eran empresas familiares con pocos trabajadores y no contaban con una tecnología adecuada para sus actividades, ni siquiera podían disponer de la energía eléctrica suficiente, pues en la época eran normales los cortes en el suministro eléctrico para ahorrar energía. Según testigos de la época, el mármol se bajaba de las canteras en carretas tiradas por bueyes, pues los medios mecánicos, los camiones, eran escasísimos en la época. Los que había estaban técnicamente desfasados y no se encontraban con facilidad piezas de recambio. Además, al no existir un puente sobre el río Almanzora, cuando éste crecía en su caudal, era imposible recibir la materia prima pues las carretas y camiones no podían vadearlo.

Por otra parte escaseaban también los pertrechos necesarios para la actividad en los talleres. Son reiteradas las peticiones que realizan los empresarios para obtener fleje y alambre mediante el sindicato. Es una muestra más de las difíciles condiciones de vida que se dieron en esta época. Estas peticiones se realizaban a través del sindicato y ello nos sirve de ejemplo para ver el rígido control que las autoridades franquistas imponían en la vida económica con la política autárquica.

Los empresarios olulenses o aquellos que escogieron el municipio como lugar de inversión, pues alguno de ellos provenían en su mayoría de tierras alicantinas. Baltasar Requena González, Mariano Ballester López, Aureliano Ais Cea. José E. García Pérez, Amador Martínez Valdés, Miguel E. Nevot, Carlos Tortosa, Tijeras y Hermanos, etc., piden reiteradamente ser suministrados con flejes y alambres a través del sindicato o mediante su influencia en la Falange. A este respecto y según los documentos estudiados, cabría preguntarse si estas empresas que acabamos de mencionar serían las más importantes por su volumen de negocios y en consecuencia las que más necesitasen los productos necesarios para el desarrollo de la actividad industrial o simplemente las que tenían mejores contactos políticos o con los sindicatos.

Por el momento sólo podemos añadir que algunos empresarios formaban parte de la oligarquía política del pueblo, caso de Aureliano Ais Cea o Baltasar Requena González y que algunas empresas se vieron en dificultades económicas como por ejemplo Amador Martínez
Valdés que fue denunciado en 1948 por no pagar unas letras de cambio y que en marzo de 1949 se vio abocada a un expediente de crisis.

En cuanto a la situación de la clase trabajadora cabe decir que en Olula se pagaban sueldos más bajos que en otras zonas de España, lo que explicaría de alguna manera la posible emigración, pues un obrero especializado lógicamente iría a trabajar allí donde ganase más dinero. Para un obrero especializado el sueldo estaba alrededor de unas once pesetas diarias, para un aprendiz, el salario diario se movía alrededor de las cuatro pesetas. En Madrid, por ejemplo, el salario diario para un obrero especializado era de 16,85 pesetas.

No tenemos noticia de ninguna huelga ocurrida durante esos años en la localidad, aunque a nivel nacional se den los primeros movimientos huelguísticos en los años 1946 y 1947.

Al respecto de la lucha obrera cabe mencionar el hecho de que en octubre de 1948 el PCE sancionase oficialmente el final de la lucha guerrillera, pues en la zona de Olula del Río actuó un maquis llamado "El Carbonero", muerto por la Guardia Civil en la Sierra, y que la gente llana del pueblo lo tenía por una especie de Robín Hood, que "robaba a los ricos para dárselo a los pobres". Las fuentes orales que nos han dado esta información desconocían si el citado maquis pertenecía a alguna organización política o sindical.

Con respecto a la situación laboral, podemos decir que la situación no sería muy buena, pues en 1940 había personas sin empleo en el municipio, en el que funcionaba una Oficina de Colocación Obrera. Esta funcionaba como su propio nombre indica como una agencia de empleo a la que debían remitirse los patronos a la hora de contratar a algún nuevo empleado. Sería una especie de antecesora del INEM moderno. Esta oficina es una muestra más del control que el nuevo Estado se proponía ejercer sobre los ciudadanos ya que intentaba regular el mercado de trabajo. Podemos decir que en el pueblo se abrieron algunos expedientes contra una serie de empresas que contrataron a trabajadores sin pasar por la Oficina de Colocación Obrera.

\section{4.- VIDA SOCIAL.}

La vida social en el pueblo tuvo que adaptarse a las nuevas circunstancias políticas del país. Así, lo que más llama la atención es el férreo control 
que se llevaba a cabo por parte de las distintas administraciones del estado en todo lo concerniente a la vida social de los ciudadanos. Como botón de muestra podemos mencionar los reiterados escritos que se suceden a lo largo de la década solicitando el número de salas de cine que funcionaban en el pueblo y el título y género de las películas exhibidas en ellas.

Este control estatal se refleja también en el racionamiento, pues en virtud del mismo, llegó a establecerse la obligatoriedad de comprar en los establecimientos autorizados para el comercio. En el caso de Olula del Río, existían tres panaderías en 1944, la $\mathrm{n}^{\circ}$. 1 propiedad de Federico Sánchez Carmona, la ${ }^{\circ} .2$ propiedad de Antonio Valdés Tapia y la $n^{\circ} .3$ de José Tapia. También hemos podido contar la existencia de tres comercios de ultramarinos, pertenecientes a María González Marhuenda, Luis Sánchez González y Juan Manuel González. Todos estos establecimientos, tanto panaderías como comercios de ultramarinos, estaban obligados a llevar un censo de las personas que adquirían productos en ellos con el fin de racionar los productos alimenticios y de evitar que éstos fuesen mal repartidos. Pero dicho propósito no se cumplió debido a las dificultades económicas de la época, pues había familias que revendían los productos que obtenían del racionamiento para atender otras necesidades.

En esta época en la que las libertades básicas de los ciudadanos habían sido eliminadas encontramos múltiples ejemplos de control y represión. Así en la época era necesario disponer de un salvaconducto, que normalmente era otorgado por el alcalde, con el beneplácito del jefe local de la Falange, para desplazarse fuera de los municipios. Asimismo, las autoridades locales son requeridas repetidamente para dar fe de algunos de los habitantes del municipio. Es el caso de la emisión de certificados de adición al movimiento de los reclutas llamados a filas, que son calificados como adictos o indiferentes al régimen.

Otro hecho que hemos constatado es que en la década de los años cuarenta en el ejército español eran incorporados reclutas que habían pertenecido al ejército de la República, así lo demuestran numerosos avales que son presentados por aquellos en el momento de incorporarse a filas, avales firmados por las autoridades locales y que respondían de la conducta de dichos reclutas, alegando en la mayoría de los casos que su presencia en el "ejército rojo" había sido forzada por las circunstancias bélicas de la Guerra Civil.

Como título anecdótico hemos encontrado un documento de 1949, que nos refleja la cruda realidad económica de la época, pues en él vemos la indumentaria que recibía un recluta al incorporarse a filas: "Un par de alpargatas, un par de calcetines, una camisa, una toalla, un calzoncillo, un mono, una gorra, un pantalón de gimnasia, una correa, un espejo, una brocha, unas tijeras y un pantalón".

También, como muestra del control social, tenemos una comunicación del gobierno civil, de febrero de 1949, en la que se recuerda que continúa en vigor la prohibición de la celebración del carnaval. Pero no todo iban a ser prohibiciones, así sabemos que la Feria del pueblo se celebraba a mediados de septiembre y que por ello algunas calles se engalanaban con bombillas.

Sin embargo, el ambiente social que existía en el pueblo lo podemos definir como un sentimiento de miedo, de miedo colectivo, miedo a la represión de las autoridades, miedo al hambre, miedo a otra conflagración bélica. Es un miedo que podemos calificar de inconsciente, pues se adueñó de las conciencias de las gentes y sirvió para que éstas se resignasen y se olvidasen de protestar contra las injusticias del régimen y contra las difíciles condiciones económicas. Un miedo que convertía en dóciles ciudadanos a las hasta entonces "gentes republicanas". Sin embargo, no todo era una balsa de aceite, pues en el juzgado municipal, abundan las denuncias por deudas o por hurto de hortalizas o frutos, por invasiones de tierras buscando pastos para el ganado, y es que cuando el hambre aprieta es posible vencer ese miedo que atenazaba las conciencias.

Finalmente, y para concluir, señalar solamente que al estudiar los documentos de esta época, vemos los diferentes tratamientos que existían. Cuando las comunicaciones son de la Falange, los "camaradas" se tutean, sin embargo, cuando las comunicaciones provienen de la administración del estado, sea civil o militar, el tratamiento empleado es más frío, de usted. Asimismo, el saludo, ¡Por Dios, España y su Revolución Nacional Sindicalista! aparece en los textos de la Falange, mientras que los escritos administrativos terminan con un Dios guarde a usted muchos años. 


\section{5.- REFERENCIAS BIBLIOGRÁFICAS.}

Avilés Fernández, M., Madrazo Madrazo, S., Mitre Fernández, E., Palacios Martín, B. \& Redondo Castro, I., (1985). El Siglo XX. De la Segunda República a nuestros días, Nueva Historia de España. Madrid: EDAF.
Bahamonde Magro, Á. (1993). La sociedad española de los años 40. Cuadernos del mundo actual. Historia 16. Madrid.

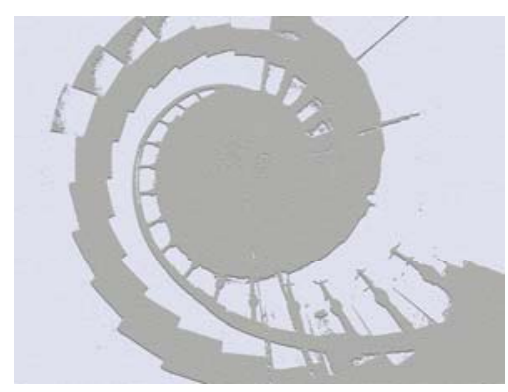

